\title{
KCNK5 is Functionally Down-Regulated Upon Long-Term Hypotonicity in Ehrlich Ascites Tumor Cells
}

\author{
Signe Skyum Kirkegaard ${ }^{a}$ Tune Wulffa,b Steen Gammeltoft ${ }^{c}$ \\ Else Kay Hoffmann ${ }^{a}$ \\ aSection of Cell and Developmental Biology, Institute of Biology, University of Copenhagen, \\ Copenhagen, ${ }^{b}$ National Food Institute, Technical University of Denmark, Kgs. Lyngby, 'Molecular \\ Biology, Sleep Research Unit, Diagnostic Department, Glostrup Hospital, Glostrup, Denmark
}

\section{Key Words}

KCNK5 • TASK-2 • Long-term volume regulation - RVD

\begin{abstract}
Background/Aims: Regulatory volume decrease (RVD) in response to acute cell swelling is well described and KCNK5 (also known as TASK-2 or $\mathrm{K}_{2 \mathrm{p}} 5.1$ ) has been shown to be the volume sensitive $\mathrm{K}^{+}$channel in Ehrlich cells. Very little is, on the other hand, known about the effects of long-term hypotonicity on expression and function of KCNK5, thus we have investigated the effect of long-term hypotonicity $(24 \mathrm{~h}-48 \mathrm{~h})$ on KCNK5 in Ehrlich cells on the mRNA, protein and physiological levels. Methods: Physiological effects of long-term hypotonicity were measured using patch-clamp and Coulter counter techniques. Expression patterns of KCNK5 on mRNA and protein levels were established using real-time qPCR and western blotting respectively. Results: The maximum swelling-activated current through KCNK5 was significantly decreased upon $48 \mathrm{~h}$ of hypotonicity and likewise the RVD response was significantly impaired after both 24 and $48 \mathrm{~h}$ of hypotonic stimulation. No significant differences in the KCNK5 mRNA expression patterns between control and stimulated cells were observed, but a significant decrease in the KCNK5 protein level $48 \mathrm{~h}$ after stimulation was found. Conclusion: The data suggest that the strong physiological impairment of KCNK5 in Ehrlich cells after long-term hypotonic stimulation is predominantly due to down-regulation of the KCNK5 protein synthesis.
\end{abstract}


Kirkegaard et al.: Long-Term Hypotonicity and Volume Regulated Channels

\section{Introduction}

Mammalian cells, with some exceptions, are susceptible to changes in intra- or extracellular amount of osmolytes due to the combination of aquaporins present in the membrane and an osmotic pressure across the membrane. An acute decrease in extracellular or increase in intracellular osmolarity respectively, will in most cells result in water uptake and thus in cell swelling. The cell homeostasis is very vulnerable to volume changes and to counteract swelling the cell possess different regulatory mechanisms involving efflux of osmolytes through ion channels and membrane transporters - a response known as regulatory volume decrease (RVD). It is estimated that $70 \%$ of the osmolyte efflux in Ehrlich ascites tumor (EAT) cells during RVD is $\mathrm{KCl}$ efflux [1] and the remaining $30 \%$ is due to the efflux of organic osmolytes [2]. For a detailed description of the mechanisms of volume regulation see $[3,4]$. In EAT cells and Ehrlich lettré ascites (ELA) cells the volume sensitive channels are the two-pore domain $\mathrm{K}^{+}$channel KCNK5 (also known as TASK-2 - TWIK-related Acid-Sensitive $\mathrm{K}^{+}$channel 2 or $\mathrm{K}_{2 \mathrm{P}}$ 5.1) [5-7], and the volume regulated anion channel (VRAC, $\mathrm{I}_{\mathrm{Cl}, \text { vol }}$ ] [8]. KCNK5 has, besides in Ehrlich cells [5-7], also been shown to be involved in RVD in other cell types including mouse proximal tubules [9], T lymphocytes [10,11], murine spermatozoa [12] and retinal glial cells [13]. It has previously been shown that the rate limiting factor in RVD in EAT cells is the volume sensitive $\mathrm{K}^{+}$efflux and thus the efflux through the KCNK5 channel [14], making an altered RVD response very likely to be due to changes related to this channel. For a recent review on KCNK5 see [15].

Response to hypotonicity can be divided into an acute and a long-term phase. The acute phase, which includes RVD, happens within minutes of cell swelling. During longtime exposure to osmolarity changes, the cell uses other mechanisms to ensure a steady intracellular environment, such as an altered gene expression and an altered protein synthesis [16]. The role of KCNK5 in acute volume regulation is well described in different cell types (see above). It has previously been shown how the KCNK5 channel is tyrosine phosphorylated after acute cell swelling in an time dependent manner [17] and recently it has been shown how KCNK5 is inhibited by G $\beta \gamma$ subunits of heteromeric G protein and thereby how a G protein coupled mechanism also can regulate the KCNK5 channel [18].

Effects of long-term hypertonicity is well studied and is known to elicit an increase in gene transcription of a number of osmoregulatory genes, which will affect the uptake and synthesis of organic osmolytes (see $[4,19])$. On the other hand only very limited work has been done on the effects of long-term hypotonicity on cells, thus a potential role for KCNK5 in long-term regulation has never been studied. Preliminary studies (referred in [4]) using micro array screening suggested that the expression of KCNK5 is 2.7 times down-regulated after 48 hours in a hypotonic medium correlating with preliminary measurements of the maximum swelling-activated KCNK5 current. The purpose of this study was thus to examine the effect of long-term hypotonicity on mRNA-, protein- and functional levels of the KCNK5 channel.

\section{Materials and Methods}

Solutions and materials

Hypotonic media (180 m0sm) for long-term hypotonic stimulation was obtained by diluting growth media with buffered water, containing $5 \mathrm{mM}$ HEPES, 10\% fetal bovine serum (FBS) and 1\% penicillin/ streptomycin (p/s), pH 7.4. The solution was sterile filtered before use. Patch-clamp experiments: hypotonic $\mathrm{NaCl}$ Ringer's solution (180 mOsm) contained in mM: $71 \mathrm{Na}^{+}, 5 \mathrm{~K}^{+}, 1 \mathrm{Mg}^{2+}, 1 \mathrm{Ca}^{2+}, 38 \mathrm{Cl}$, 33 gluconate, 10 HEPES, pH 7.4. Isotonic Ringer's solution (300 mOsm) was generated by addition of $110 \mathrm{mM}$ mannitol and contained only $5 \mathrm{mM}$ HEPES. The pipette solution contained in mM: $2 \mathrm{Na}^{+}, 116 \mathrm{~K}^{+}, 1.2 \mathrm{Mg}^{2+}, 42.4 \mathrm{Cl}^{-}, 62$ gluconate, 10 HEPES, 30 mannitol, 10 EGTA, 2.5 ATP and 0.1 GTP. Coulter counter experiments: hypotonic Ringer's solution (180mOsm) contained in $\mathrm{mM}: 72 \mathrm{Na}^{+}, 74.5 \mathrm{Cl}^{-}, 2.5 \mathrm{~K}^{+}, 0.5 \mathrm{Mg}^{2+}, 0.5 \mathrm{SO}_{4}^{2-}, 0.5 \mathrm{HPO}_{4}^{-}, 0.5$ $\mathrm{Ca}^{2+}$, 3.3 MOPS, 3.3 TES and 5 HEPES, pH 7.4. Isotonic Ringer's solution (300 mOsm) was obtained by the addition of sucrose. 


\section{Cell cultures}

ELA cells and EAT cells were cultured in RPMI ${ }_{1640}$ media supplemented with $10 \% \mathrm{FBS}$ and $1 \% \mathrm{p} / \mathrm{s}$ at $37{ }^{\circ} \mathrm{C}$ and $5 \% \mathrm{CO}_{2}$. EAT and ELA cells were maintained by transferring $1 \mathrm{ml}$ cell suspension to $10 \mathrm{ml}$ fresh $\mathrm{RPMI}_{1640}$ medium every 3-4 days. ELA cells were loosened from the surface by trypsination, $1.5 \mathrm{ml} 0.25 \%$ trypsine/EDTA solution per T-75 culture flask. Only passages 6-30 were used for experiments.

\section{Patch-clamp measurements}

ELA cells were kept in isotonic (300 mOsm) or hypotonic medium (180 mOsm) for 24 or 48 hours and transferred to $25 \mathrm{~mm}$ cover-slips after which they were placed in a chamber mounted on an inverted microscope (Zeiss Axiovert 10, Carl Zeiss, Germany). Solution shifts were generated using gravity-fed and pump-suction mechanisms. The current was measured using standard whole-cell patch-clamp using a suitable amplifier (Axopatch 200B, Axon instruments, California, USA). A Digidata 1200 Interface board and pClamp7 software (Axon Instruments) were used to generate voltage-clamp command voltages, and to digitize data. In the cell attached configuration, prior to establishing the whole-cell configuration the fast capacity transients were eliminated. Following whole-cell formation, the series resistance and the wholecell capacitance were compensated and annulled with mean values that did not change significantly during experiments [20]. Pipettes were made from Vitrex glass capillary tubing with an outside diameter of 1.7 mm (Modulohm, Herlev, Denmark) using a Narishige PP-830 puller (Tokyo, Japan) and had resistances of $\approx 4 \mathrm{M} \Omega$. All experiments were carried out at $37^{\circ} \mathrm{C}$.

IK was measured as previously described in [5]. Briefly, the membrane potential was clamped in pulses of $500 \mathrm{~ms}$ at the equilibrium potential for $\mathrm{Cl}^{-}$which was $5 \mathrm{mv}$ during isotonic conditions and 0 mv under hypotonic conditions and these reversal potentials have previously proven to be good estimates $[5,6,21]$. The voltage correction was due to a dilution of the intracellular ion compositions as a result of hypotonicity and the following cell swelling. The current increase was measured after 300 sec of hypotonic stimulation and taken relative to the cell membrane surface $(\mathrm{pF})$.

\section{mRNA measurements}

ELA and EAT cells were stimulated with hypotonic media (180 mOsm) or isotonic media (300 mOsm) for 24 or 48 hours and lysed in RNA lysis buffer (Machery-Nagel, Düren, Germany). RNA was purified from lysates using NucleoSpin $®$ RNA II (Macherey-Nagel, Düren, Germany) according to manufacturer's instructions. Reverse transcriptase PCR with SuperScript II and oligo(dT) $)_{12-18}$ primer (Invitrogen, Life Technologies, Naerum, Denmark) was used to generate cDNA from the purified mRNA and performed on an Eppendorf Mastercycler. In a total of $10 \mu \mathrm{lddH_{2 }}$ O, dNTP mix $(500 \mu \mathrm{M})$ and oligo(dT) ${ }_{12-18}$ primer $(500 \mathrm{ng})$ was mixed on ice, $1 \mu \mathrm{g}$ mRNA was added and incubated for $5 \mathrm{~min}$ at $65^{\circ} \mathrm{C}$. The solution was put on ice and briefly centrifuged. $4 \mu \mathrm{l} 5 \mathrm{x}$ first strand buffer, DTT $(10 \mu \mathrm{M})$ and $1 \mu \mathrm{ldd \textrm {H } _ { 2 }} \mathrm{O}$ was subsequently added and the solution incubated for $2 \mathrm{~min}$ at $42{ }^{\circ} \mathrm{C}$. $1 \mu \mathrm{l}$ SuperScript II was added and incubated at $42{ }^{\circ} \mathrm{C}$ for $50 \mathrm{~min}$ followed by incubation at $70{ }^{\circ} \mathrm{C}$ for $15 \mathrm{~min}$ and ending at $4{ }^{\circ} \mathrm{C}$. Real-time qPCR was performed in triplicates using the Stratagene MX4000 PCR system, Brilliant ${ }^{\circledR}$ II SYBR $®$ Green QPCR Master Mix (Stratagene, Agilent Technologies) and the following primers: mKCNK5 forward: 5'-GTC AAG GCC ACT TGG TGA GG-3' and mKCNK5 reverse: 5'-TGC TGG TGA AGG TGG ACT CA-3' (KCNK5 GenBank accession number NM_021542) and ARP: mARP forward: 5'-CGA CCT GGA AGT CCA ACT AC-3' mARP reverse: 5'-ACT TGC TGC ATC TGC TTG-3' (GenBank accession number NM_007475), which was used as reference gene. $10 \mu$ l Master Mix, $0.4 \mu \mathrm{l}$ forward and reverse primer (200 $\mathrm{nM}$ final concentration), $0.4 \mu \mathrm{l} 500 \mathrm{x}$ diluted ROX II reference dye

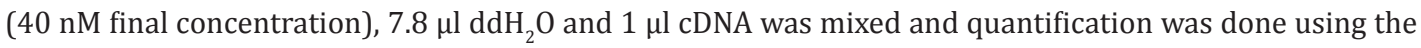
following cycles: $95{ }^{\circ} \mathrm{C} 10 \mathrm{~min}$ and $95^{\circ} \mathrm{C} 30 \mathrm{sec}, 58{ }^{\circ} \mathrm{C} 1 \mathrm{~min}, 72^{\circ} \mathrm{C} 30 \mathrm{sec} \times 40$. Standard curves were done in order to measure primer efficiency which was adjusted for in calculations. Primers were selected using Primer3 software and purchased from MWG Eurofins (Germany). Quantification was carried out using the Pfaffl method [22].

\section{SDS-PAGE and western blotting}

ELA and EAT cells were stimulated with isotonic or hypotonic media for 24 or $48 \mathrm{~h}$ and subsequently lysed in $95^{\circ} \mathrm{C}$ lysis buffer (10 mM Tris- $\mathrm{HCl} \mathrm{pH} \mathrm{7.4,1 \%} \mathrm{SDS} \mathrm{and} 20 \mathrm{mM}$ EDTA) with protease inhibitors (Roche Applied Science) and phosphatase inhibitors added. SDS-PAGE and western blotting were performed as previously described [17]. Briefly, we used a SDS-PAGE-western blotting system from Invitrogen (Lfe 
Fig. 1. Activity of KCNK5 current in ELA cells upon long-term hypotonic stimulation. Cells were kept in isotonic (300 mOsm) or hypotonic medium (180 m0sm) for 24 or 48 hours. The maximum swellingactivated $\mathrm{K}^{+}$current was measured using standard whole-cell patch-clamp. The current increase was measured after $300 \mathrm{sec}$ of hypotonic stimulation $(n=3)$ and taken relative to the cell membrane surface $(\mathrm{pF})$. Student's T-test was used to test for statistical significance and one star $(*)$ indicate a 95\% significance level.

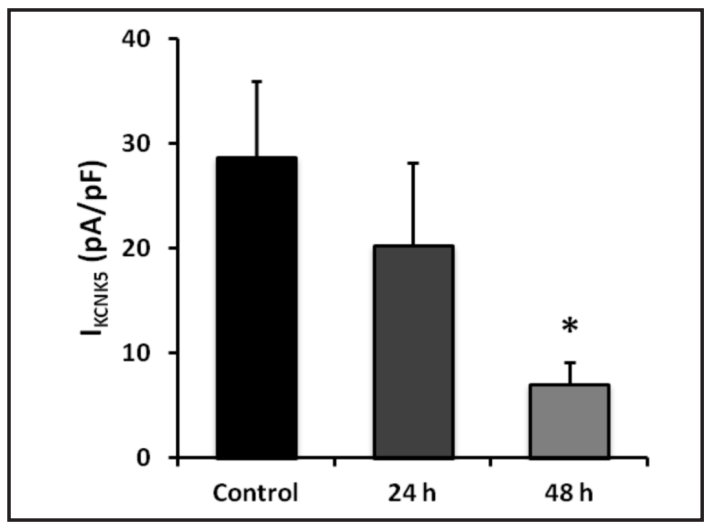

technologies) and with the following antibodies; KCNK5 (Alomone Lab., Israel) 1:250 and $\beta$-actin (SigmaAldrich) 1:1000. Since we use two different antibodies on every blot, membranes were cut around $50 \mathrm{kDa}$ letting us visualize both KCNK5 and $\beta$-actin (65 and $42 \mathrm{kDa}$ respectively) using BCIP/NBT. Protein bands were quantified using UN-SCAN-IT software.

\section{Cell membrane protein labeling and purification}

ELA cells were grown in 40\% hypotonic medium (180 mOsm, standard medium diluted with buffered water, see above) or isotonic medium (300 mOsm, standard medium) for $48 \mathrm{~h}$ before cell membrane purification. Cell membrane proteins were isolated using Pierce Cell Surface Protein Isolation Kit (Thermo Fisher Scientific) according to manufactures instructions. SDS-PAGE and western blotting was used to analyze the amount of KCNK5 in whole cell lysate as well as purified samples (see above).

\section{Cell volume measurements}

Absolute cell volume was measured by electronic cell sizing using the Coulter Multisizer ll (Coulter, Luton, UK) with a tube orifice of $100 \mu \mathrm{m}$. For each experiment $2.5 \times 10^{6}$ cells were used and cell volume was determined as the median of the cell volume curves after calibration with latex beads $(15 \mu \mathrm{m})$. Cells were either kept in isotonic ( $300 \mathrm{mOsm}$ ) medium or in a $40 \%$ hypotonic medium for 24 or $48 \mathrm{~h}$. Prior to cell volume measurements cells were centrifuged and resuspended in standard medium (isotonic) were they were kept for $30 \mathrm{~min}$ in order to acclimatize before experiencing a hypotonic chock. The duration in standard medium allowed the cells to adapt to the changed environment without influencing protein synthesis and gene transcription. It should be mentioned that the cells shrink when transferred from the hypotonic into the isotonic medium and thus perform a regulatory volume increase (RVI) process. As KCNK5 channels are inhibited in shrunken cells $[7,18]$ we have included the $30 \mathrm{~min}$ isotonic acclimatization period and have controlled that there is no significant difference between the cell volumes in the three experimental groups. The mean isotonic, the $24 \mathrm{~h}$ and $48 \mathrm{~h}$ hypotonic pre-treatment cell volumes were $803.7 \pm 61.5 \mu \mathrm{m}^{3}, 829.7 \pm 58$ $\mu \mathrm{m}^{3}$ and $783.7 \pm 46.9 \mu \mathrm{m}^{3}$ respectively, with no significant difference between the control and pre-treated cells.

All Ringer's solutions were micro-filtered (Millipore, $0.45 \mu \mathrm{M}$ ) before use. Volume recovery was estimated as $\left(\mathrm{V}_{\max }-\mathrm{V}_{4 \min }\right) /\left(\mathrm{V}_{\max }-\mathrm{V}_{\text {iso }}\right)$, where $\mathrm{V}_{\max }, \mathrm{V}_{4 \min }$ and $\mathrm{V}_{\text {iso }}$ are the maximal cell volume, cell volume at time 4 min and cell volume under isotonic conditions, respectively.

Statistics

Student's T-test and one-way analysis of variance (ANOVA) was used to test for statistical significance. $95 \%$ and $99 \%$ levels of significance were shown by one star or two stars respectively.

\section{Results}

Patch-clamp studies revealed a decreased maximum swelling-activated current in ELA cells upon 48 h of hypotonicity

Fig. 1 shows the maximum swelling-activated $\mathrm{K}^{+}$current through the volume sensitive $\mathrm{K}^{+}$channel and it is seen that after $24 \mathrm{~h}$ there is a decreased $\mathrm{K}^{+}$current (not significant). This 


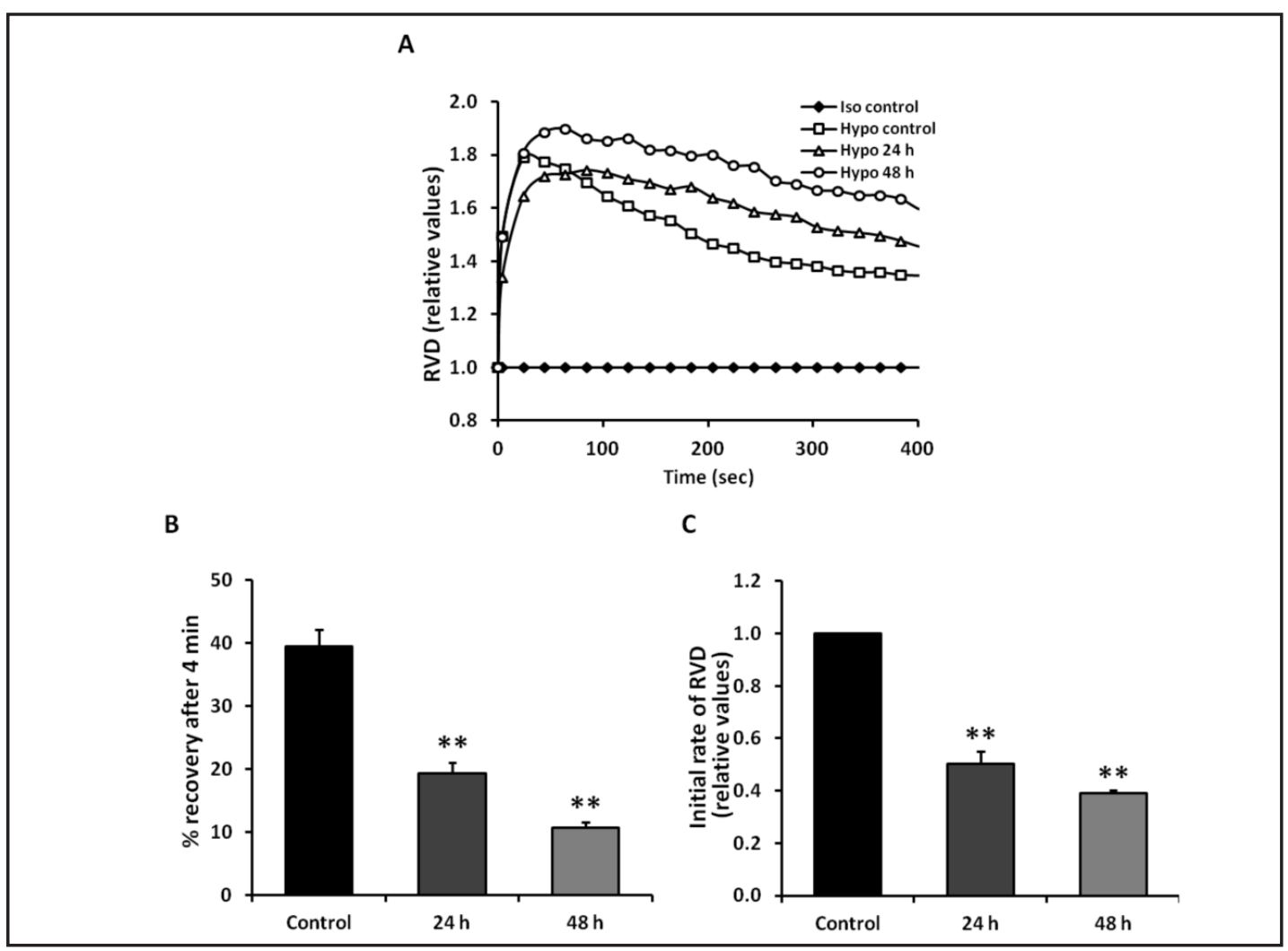

Fig. 2. RVD in EAT cells. A Coulter counter was used to measure the volume of isotonic control (300 mOsm) and long-term (24 or $48 \mathrm{~h}$ ) hypotonically (180 mOsm) treated EAT cells. A: representative figure showing relative RVD over time (sec) for untreated control cells and cells kept in hypotonic medium for 24 or $48 \mathrm{~h}$. B: Mean volume recovery of $n=5$ experiments after 4 min was calculated as $\left(V_{\max }-V_{4 \min }\right) /\left(V_{\max }-V_{\text {iso }}\right)$, where $\mathrm{V}_{\max }, \mathrm{V}_{4 \min }$ and $\mathrm{V}_{\text {iso }}$ are the maximal cell volume, cell volume at time $4 \mathrm{~min}$ and cell volume under isotonic conditions, respectively. C: initial rate of RVD or the slope was calculated $(n=5)$ using linear regression on the linear part of the RVD curve, from maximum volume to the end of linearity. One-way ANOVA was used to test for statistical significance and two stars ${ }^{* *}$ ) indicate a 99\% significance level.

is supported by experiments measuring $\mathrm{K}^{+}$efflux after $24 \mathrm{~h}$ hypotonic incubation using ${ }^{86} \mathrm{Rb}^{+}$ as a tracer. We found that the rate constant for the swelling-activated $\mathrm{K}^{+}$efflux in stimulated cells was lower than in control cells. At 12 minutes after cell swelling the rate constant was 0.0134 in stimulated cells compared to 0.0154 in the control cells (data not shown), thus supporting the results obtained by patch-clamp. After $48 \mathrm{~h}$ of hypotonicity the maximum swelling-activated current through KCNK5 was significantly decreased from $28.7 \pm 7.2 \mathrm{pA}$ / $\mathrm{pF}$ to $7.0 \pm 2.1 \mathrm{pA} / \mathrm{pF}$ corresponding to a decrease of $75.6 \%$.

\section{Long-term exposure to hypotonicity (24 and $48 \mathrm{~h}$ ) decreased RVD in EAT cells}

In addition we studied the effect of 24 and 48 hours hypotonicity ( $180 \mathrm{mOsm}$ ) on RVD in EAT cells (Fig. 2) and found that after both $24 \mathrm{~h}$ and 48h RVD was significantly decreased both when looking at \% recovery after $4 \mathrm{~min}$ (Fig. $2 \mathrm{~A}+\mathrm{B}$ ) and at the initial rate of RVD (Fig. $2 \mathrm{~A}+\mathrm{C}) .24 \mathrm{~h}$ of hypotonic stimulation resulted in a decreased RVD when re-exposing the cells to hypotonicity, with a recovery after 4 minutes of $19.3 \pm 1.33 \%$ compared with $41.5 \pm 2.51 \%$ seen in the control cells (Fig. 2B), corresponding to a $53 \%$ decrease. When looking at the initial rate of RVD, $24 \mathrm{~h}$ of hypotonicity resulted in a relative decrease in the rate of RVD to $46.5 \pm 3.79 \%$ compared to untreated control cells (Fig. 2D). After $48 \mathrm{~h}$ the initial rate of RVD was further decreased to $30.8 \pm 3.69 \%$ compared to untreated control cells equal to a $69 \%$ RVD inhibition (Fig. 2D). The \% recovery after 4 min was decreased to $12 \pm 1.51 \%$ compared to $41.5 \pm 2.51 \%$ of the control cells corresponding to a $71 \%$ decrease after $48 \mathrm{~h}$ of hypotonicity. 


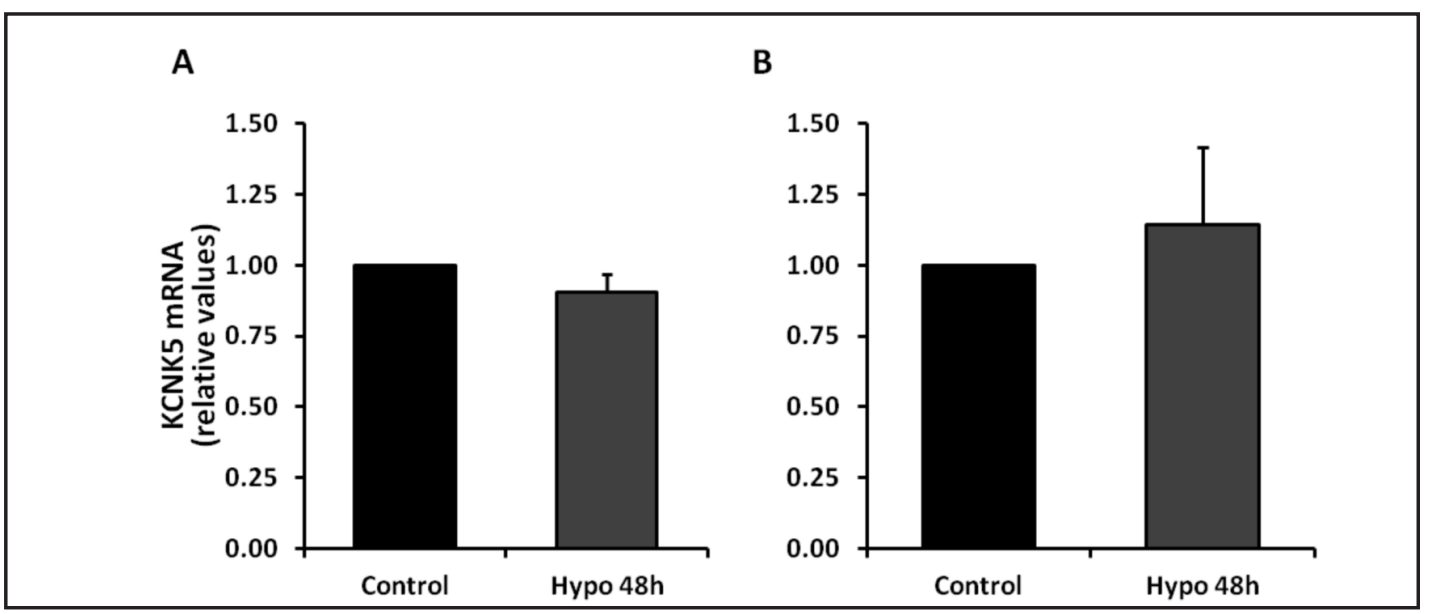

Fig. 3. mRNA levels of KCNK5 in ELA and EAT cells. ELA (A) $(n=4)$ and EAT (B) $(n=5)$ cells were stimulated with hypotonic (180 mOsm) or isotonic media (300 mOsm) for 24 or 48 hours and real-time qPCR was performed. Student's T test or one-way ANOVA was used to test for statistical significance.

There was no significantly change in mRNA levels in EAT and ELA cells upon long-term hypotonicity

To further elucidate the nature of the decreased physiological function of the KCNK5 channel we investigated the expression of KCNK5 on mRNA and protein levels.

Real-time qPCR was performed on treated (48h of hypotonicity) and untreated (control) EAT and ELA cells and fig. 3 shows the mRNA expression data for ELA (Fig. 3A) and EAT (Fig. $3 \mathrm{~B})$ cells upon long-term hypotonicity. It is seen that even though there is a $10.6 \%$ decrease in mRNA levels in $48 \mathrm{~h}$ hypotonically treated ELA cells compared to the untreated control cells the decrease is not significant. In the EAT cells an apparent increase in KCNK5 mRNA was detected, though the difference was also not significant.

KCNK5 protein levels were significantly decreased in EAT and ELA cells upon 48h of hypotonically exposure

Western blot analysis on EAT and ELA cells revealed a significant decrease in KCNK5 protein expression levels after $48 \mathrm{~h}$, but not after $24 \mathrm{~h}$ of hypotonically stimulation. Fig. $4 \mathrm{~A}$ shows how the mean KCNK5 protein level in EAT cells is approximately the same in both control cells and after $24 \mathrm{~h}$ of hypotonicity, but is significantly decreased to $70 \pm 4.4 \%$ after $48 \mathrm{~h}$ of treatment. The same analysis in ELA cells likewise revealed a significant difference between protein amount in control and treated cells (Fig. 4B). After 48h of hypotonicity a $\approx 30 \%$ decrease to $70.9 \pm 12.2 \%$ was seen, while an apparent increase (not significant) after $24 \mathrm{~h}$ was observed. The results were confirmed in a single experiment by measuring cell surface KCNK5 protein amount using membrane protein biotinylation and showing how $48 \mathrm{~h}$ of hypotonic treatment decreases the amount of KCNK5 protein inserted into the ELA membrane by approximately $50 \%$, thus confirming and not very different from the decrease seen in total KCNK5 protein (see Fig 4C).

\section{Discussion}

Since the KCNK5 channel is a very important player in the RVD response in Ehrlich cells, we investigated a possible effect of long-term hypotonicity on RVD and on KCNK5 mRNA and protein expression. The RVD measurements were performed on the EAT cell line using a Coulter Counter. EAT cells were chosen for these volume measurements since the most accurate volume measurements are obtained on cells in suspension. A significant 
A

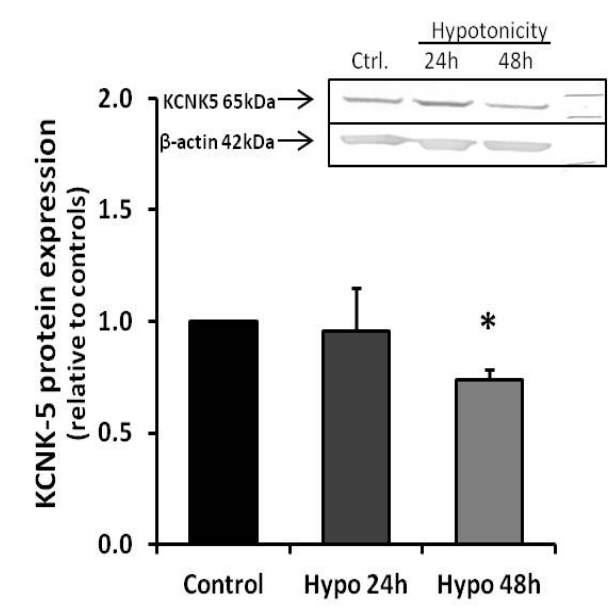

B

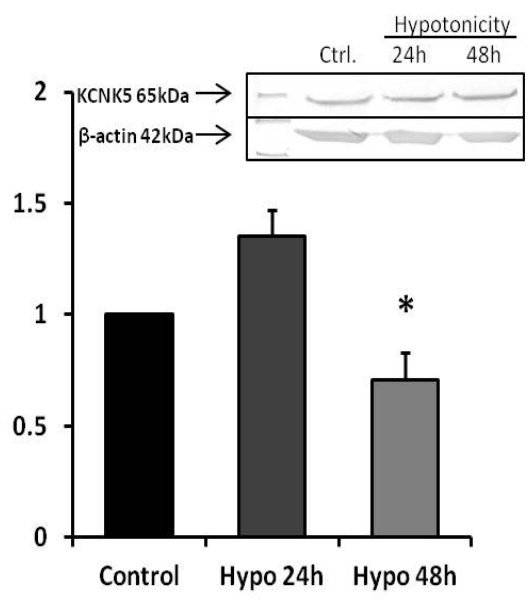

C $\leftarrow$ KCNK5 65kDa

Fig. 4. KCNK5 protein levels in Ehrlich ascites tumor and Ehrlich Lettré ascites cells. Cells were isotonic (300mOsm) or hypotonically $(180 \mathrm{mOSm})$ treated for 24 or 48 hours and SDS-PAGE and western blotting were performed using antibodies against KCNK5 and $\beta$-actin. A: representative western blot and mean protein levels ( $n=3)$ in EAT cells. B: representative western blot and mean protein levels $(n=9)$ in ELA cells. C: membrane purification $(n=1)$ showing KCNK5 protein amount inserted into the ELA membrane under control and 48h hypotonic conditions. Student's T-test was used to determine statistical significance and one star $(*)$ represents a statistical significance level of $95 \%$.

impairment of RVD was found both after 24 and 48 hours of long-term exposure to the hypotonic medium. The inhibited RVD performance in EAT cells could reflect a decreased function of either KCNK5 $\left(\mathrm{K}^{+}\right)$or of VRAC $\left(\mathrm{Cl}^{-}\right)$. However since the KCNK5 channel is the rate limiting factor for RVD in these cells [14] and since patch-clamp measurements showed a decreased maximum swelling-activated current through KCNK5 upon long-term hypotonic stimulation, the results were taken to indicate a down-regulation of the KCNK5 channels or reduced ability of the KCNK5 channel during RVD.

The physiological impairment of RVD and of the maximum swelling-activated $\mathrm{K}^{+}$current through KCNK5 channels could be due to regulation on a number of levels such as I) a downregulation of KCNK5 protein synthesis II) KCNK5 mRNA transcription III) post-translational modifications resulting in an inhibited channel function IV) an unknown regulatory mechanism "turning off" the channel V) an internalization of membrane embedded channels or a combination of the above. We found that there was no significant difference between the mRNA amount of KCNK5 in control cells compared to hypotonic stimulated cells which were true in both EAT and ELA cells. Since there was no significant difference in the mRNA expression pattern between control and stimulated cells we conclude that the physiological changes most likely are not due to regulation on the transcriptional level. It might be argued that cells with down-regulated KCNK5 expression could have died before $48 \mathrm{~h}$ and this is why no decrease in mRNA level is seen. However, the fact that we do see a clear down-regulation at the protein level argues against the possibility.

Although there was no effect of long-term stimulation on gene transcription levels, we found significant lower levels of KCNK5 protein after $48 \mathrm{~h}$ of hypotonicity in both cell 
lines, thus indicating a higher degree of KCNK5 protein degradation or decreased synthesis of the KCNK5 protein. Our results were further substantiated in one experiment, where it was shown how 48h of long-term hypotonicity resulted in a decrease in KCNK5 protein present in the plasma membrane, thus supporting the theory that long-term hypotonicity decreases KCNK5 protein expression and may in addition cause an altered KCNK5 sorting to the membrane. As the decrease in membrane bound KCNK5 was not very different from the total decrease in KCNK5 protein, we have not looked further into this.

At least three factors could influence this change in KCNK5 protein expression level: the lowered ion strength, the decrease in $\mathrm{K}^{+}$concentration and the decreased $\mathrm{Cl}^{-}$concentration all generated by the response to the hypotonic medium. We speculate if e.g. the decreased $\mathrm{K}^{+}$ concentration could prompt the cells to down-regulate the $\mathrm{K}^{+}$leak-channel KCNK5 in order to govern the smaller amount of $\mathrm{K}^{+}$more strictly. The lowered $\mathrm{Cl}^{-}$concentration could result in the same mechanisms, but since we are dealing with a significant decrease in KCNK5 protein expression, we suggest that the physiological changes are predominantly due to alterations in potassium rather that in chloride level.

To our knowledge not much work has been published on long-term effects of hypotonicity on protein synthesis but it should be noted that it has been shown that protein synthesis is up-regulated in hepatocytes of air-breathing walking catfish upon hypotonicity $(\approx 2$ hours) [23]. Since we are dealing with a down-regulation of the KCNK5 protein this is thus not likely to be caused by a general effect on the protein synthesis but rather by a specific effect on the KCNK5 protein synthesis or breakdown.

There is a time discrepancy between the physiological data and the protein expression data obtained in EAT cells, since there is a significant impairment of RVD in EAT cells already after $24 \mathrm{~h}$ of hypotonicity but the down-regulation of KCNK5 protein amount is first detectable after $48 \mathrm{~h}$ of hypotonicity. It is likely that this is caused by a regulatory inhibition of the channel followed by a later decrease in protein synthesis. This has not been further investigated.

Taken together our results show that the clear physiological changes of the KCNK5 channel in Erhlich cells upon long-term hypotonic stimulation is predominantly due to a decreased protein synthesis. We cannot rule out other regulatory mechanisms as contributors to the down-regulation of the maximum swelling-activated KCNK5 current seen after longtem hypotonicity. We have previously shown how protein tyrosine kinases are vital in KCNK5 channel opening and that tyrosine phosphatases are important for the closing of the channel upon a swelling-mediated activation of the channel [17], and it has furthermore been suggested that KCNK5 activation can be modulated by G protein G $\beta \gamma$ subunits [18]. Thus an altered tyrosine kinase/phosphatase profile or changes in the G protein coupled mechanism could potentially be involved in the functional inhibition of KCNK5.

The technical skills of Dorthe Nielsen and Birthe Juul Hansen (University of Copenhagen) is gratefully acknowledged and appreciated. This work was supported by The Danish Council for Independent Research/Natural Sciences (grants 09-064182 and 10-085373) and The Lundbeck Foundation, Denmark (J Nr R32-A3102).

\section{Abbreviations}

ANOVA (Analysis of variance); ARP (Acidic ribosomal protein); cDNA (Complementary DNA); EAT (Ehrlich Ascites Tumor); EDTA (Ethylenediaminetetraacetic acid); EGTA (Ethylene glycol tetraacetic acid); ELA (Ehrlich Lettré Ascites); HEPES (4-(2-hydroxyethyl)1-piperazineethanesulfonic acid); KCNK5 (Also known as TASK-2 or $\mathrm{K}_{2 \mathrm{P}} 5.1$ ); MOPS (3-(N-morpholino)propanesulfonic acid); mRNA (messenger RNA); p/s (Penicillin/ streptomycin); $\mathrm{pA} / \mathrm{pF}$ (picoampere/picofarad); RVD (Regulatory volume decrease); TASK2 (Twik-related Acid Sensitive $\mathrm{K}^{+}$channel 2); TES (1,3-dihydroxy-2-(hydroxymethyl) propan-2-yl]amino]ethanesulfonic acid); VRAC (Volume Regulated Anion Channel); qPCR (quantitative polymerase chain reaction). 


\section{Conflict of Interest}

The authors declare no conflict of interest.

\section{References}

1 Hendil KB, Hoffmann EK: Cell volume regulation in Ehrlich ascites tumor cells. J Cell Physiol 1974;84:115125.

- Hoffmann Else K, Hendil Klavs B: The role of amino acids and taurine in isoosmotic intracellular regulation in Ehrlich ascites mouse tumour cells. J Comp Physiol 1976;108:279-286.

-3 Lang F, Busch GL, Ritter M, Völkl H, Waldegger S, Gulbins E, Häussinger D: Functional Significance of Cell Volume Regulatory Mechanisms. Physiol Rev 1998;78:247-306.

4 Hoffmann EK, Lambert IH, Pedersen SF: Physiology of Cell Volume Regulation in Vertebrates. Physiol Rev 2009;89:193-277.

5 Riquelme G, Sepúlveda FV, Jørgensen F, Pedersen S, Hoffmann EK: Swelling-activated potassium currents of Ehrlich ascites tumour cells. Biochim Biophys Acta 1998;1371:101-106.

6 Hougaard C, Niemeyer MI, Hoffmann EK, Sepúlveda FV: $\mathrm{K}^{+}$currents activated by leukotriene D4 or osmotic swelling in Ehrlich ascites tumour cells. Pflügers Arch 2000;440:283-294.

7 Niemeyer MI, Cid LP, Barros LF, Sepúlveda FV: Modulation of the Two-pore Domain Acid-sensitive $\mathrm{K}^{+}$ Channel TASK-2 (KCNK5) by Changes in Cell Volume. J Biol Chem 2001;276:43166-43174.

8 Pedersen SF, Prenen J, Droogmans G, Hoffmann EK, Nilius B: Separate Swelling- and $\mathrm{Ca}^{2+}$-activated Anion Currents in Ehrlich Ascites Tumor Cells. J Membr Biol 1998;163:97-110.

-9 Barriere H, Belfodil R, Rubera I, Tauc M, Lesage F, Poujeol C, Guy N, Barhanin J, Poujeol P: Role of TASK2 Potassium Channels Regarding Volume Regulation in Primary Cultures of Mouse Proximal Tubules. J Gen Physiol 2003;122:177-190.

10 Bobak N, Bittner S, Andronic J, Hartmann S, Mühlpfordt F, Schneider-Hohendorf T, Wolf K, Schmelter C, Göbel K, Meuth P, Zimmermann H, Döring F, Wischmeyer E, Budde T, Wiendl H, Meuth SG, Sukhorukov VL: Volume regulation of murine $\mathrm{T}$ lymphocytes relies on voltage-dependent and two-pore domain potassium channels. Biochim Biophys Acta 2011;1808:2036-2044.

11 Andronic J, Bobak N, Bittner S, Ehling P, Kleinschnitz C, Herrmann AM, Zimmermann H, Sauer M, Wiendl H, Budde T, Meuth SG, Sukhorukov VL: Identification of two-pore domain potassium channels as potent modulators of osmotic volume regulation in human T lymphocytes. Biochim Biophys Acta 2013;1828:699707.

12 Barfield JP, Yeung CH, Cooper TG: The Effects of Putative $\mathrm{K}^{+}$Channel Blockers on Volume Regulation of Murine Spermatozoa. Biol Reprod 2005;72:1275-1281.

13 Skatchkov SN, Eaton MJ, Shuba YM, Kucheryavykh YV, Derst C, Veh RW, Wurm A, Iandiev I, Pannicke T, Bringmann A, Reichenbach A: Tandem-pore domain potassium channels are functionally expressed in retinal (Müller) glial cells. Glia 2006;53:266-276.

14 Lambert IH, Hoffmann EK, Jørgensen F: Membrane potential, anion and cation conductances in Ehrlich ascites tumor cells. J Membr Biol 1989;111:113-131.

15 Cid LP, Roa-Rojas HA, Niemeyer MI, González W, Araki M, Araki K, Sepúlveda FV: TASK-2: a K2P K+ channel with complex regulation and diverse physiological functions. Front Physiol 2013;4:1-9.

16 Cohen DM: SRC family kinases in cell volume regulation. Am J Physiol Cell Physiol 2005;288:C483-C493.

$\checkmark 17$ Kirkegaard SS, Lambert IH, Gammeltoft S, Hoffmann EK: Activation of the TASK-2 channel after cell swelling is dependent on tyrosine phosphorylation. Am J Physiol Cell Physiol 2010;299:C844-C853.

18 Añazco C, Peña-Münzenmayer G, Araya C, Cid LP, Sepúlveda F, Niemeyer M: G protein modulation of K2P potassium channel TASK-2: A role of basic residues in the $C$ terminus domain. Pflugers Arch 2013;1-12.

19 Burg MB, Kwon ED, Kültz D: Regulation of gene expression by hypertonicity. Annu Rev Physiol 1997;59:437-455.

20 Hougaard C, Jørgensen F, Hoffmann EK: Modulation of the volume-sensitive $\mathrm{K}^{+}$current in Ehrlich ascites tumour cells by pH. Pflügers Arch 2001;442:622-633.

21 Niemeyer MI, Hougaard C, Hoffmann EK, Jørgensen F, Stutzin A, Sepúlveda FV: Characterisation of cell swelling-activated $\mathrm{K}^{+}$selective cunductance of ehrlich ascites tumour cells. J Physiol 2000;524:757-767.

22 Pfaffl MW: A new mathematical model for relative quantification in real-time RT-PCR. Nucleic Acids Res 2001;29:e45.

23 Biswas K, Jyrwa L, Häussinger D, Saha N: Influence of cell volume changes on protein synthesis in isolated hepatocytes of air-breathing walking catfish (Clarias-ábatrachus). Fish Physiol Biochem 2010;36:17-27. 